\title{
Assessment of an anti-ageing structured cosmetic formulation containing goji berry
}

\author{
Fernanda de Godoy Leite', João Augusto Oshiro Júnior ${ }^{2,3}$, Leila Aparecida Chiavacci², \\ Bruna Galdorfini Chiari-Andréo ${ }^{\circledR 2,4 *}$
}

\begin{abstract}
${ }^{1}$ Faculdade Hermínio Ometto, UNIARARAS, Araras/SP, ${ }^{2}$ Universidade Estadual Paulista, UNESP, Faculdade de Ciências Farmacêuticas, Araraquara/SP, ${ }^{3}$ Universidade Estadual da Paraiba, UEPB, Campina Grande/PB, ${ }^{4}$ Universidade de Araraquara, UNIARA, Araraquara/SP
\end{abstract}

\begin{abstract}
Based on previous studies, it has been found that goji berry (GB), popularly known as a 'miracle fruit', has excellent antioxidant potential and can be used in the treatment of skin disorders associated with ageing. This study aimed to incorporate GB into a structured cosmetic in order to optimise its penetration. Stability studies of the formulation, determination of the antioxidant activity of the extract and of the formulation, rheological measurements, SAXS, polarised light microscopy and bioadhesion analyses were performed. The results indicated the antioxidant activity of the extract, which can be incorporated into an emulsified cosmetic formulation. The emulsified formulation containing the extract remained stable, even after being submitted to thermal and luminous stresses for 30 days. In addition, rheological tests revealed that the addition of the GB soft extract reduced the viscosity of the formulation, increasing thixotropy and deformation. These systems were characterised by SAXS as a lamellar phase, which was confirmed by polarised light microscopy. These highly organised structures indicate their excellent stability. In vitro bioadhesion experiments revealed that these formulations exhibited skin adhesion strength statistically similar to commercial anti-ageing formulation. These results suggest that this formulation has excellent potential to be used as a topical treatment for ageing.
\end{abstract}

Keywords: Goji Berry. Skin. Formulation. Lycium/drug effects. Skin Aging/immunology. Cosmetics/ pharmacokinetics. Antioxidants/pharmacokinetics. Cosmetic Technology.

\section{INTRODUCTION}

The skin is a complex covering organ and is the largest organ in the human body, with functions such as pigmentation, keratogenesis, thermoregulation, sweating, defence and absorption. It consists of two layers: the outer epidermis outermost and the inner dermis. The hypodermis, or subcutaneous tissue, lies just below the dermis. This tissue is not part of the skin, but represents a region of union between the skin and other organs (Batistela, Chorilli, Leonardi, 2007; Alchorne, Abreu, 2008).

Over time, some changes occur in tissues due to ageing. In the skin, these changes are more visible. The most apparent signs of senile skin are atrophy, wrinkling, ptosis, lassitude, dyschromia, among others (Oriá et al.,

\footnotetext{
*Correspondence: B. G. Chiari-Andréo. Universidade de Araraquara, UNIARA, Rua Carlos Gomes, 1338, zip code: 14801-340, Araraquara/SP - Brasil. E-mail: chiari-andreob@uniara.com.br
}

2003). The skin ageing process can occur due to various factors, including intrinsic or chronological ageing and extrinsic ageing (Velasco et al., 2004). Changes in the genetic material of cells, including those that compose the skin, may occur during the skin ageing process. This phenomenon generates protein alterations and decreases cellular proliferation, with a consequent loss of elasticity and vigour. This process is accelerated by chemical and enzymatic oxidation in which there is the formation of free radicals (Hirata, Sato, Santos, 2004).

Free radicals are organic and inorganic molecules that contain one or more unpaired electrons, making them highly unstable and chemically reactive. The presence of free radicals is critical to the maintenance of normal physiological functions (Bianchi, Antunes, 1999). Conversely, antioxidants are compounds that inhibit or retard the oxidation of molecules by preventing chain oxidation reactions from starting or spreading. The antioxidant activity of a compound may be due to its 
oxide-reducing properties, with a role in the neutralisation of free radicals. Antioxidant agents can be both naturally occurring and synthetic (Degáspari, Waszczynskyj, 2004).

The main sources of antioxidants to the human body are food or dietary supplementation. However, other ways of affecting body homeostasis through antioxidants have been used and studied. Flavonoids, found in red fruits, have present phenolic groups in their chemical structure, with iron chelating power and action against free radicals (Silva, Degáspari, 2014). Among the red fruits, goji berry (Lycium barbarum L.) (GB), belonging to the Solanaceae family, has received attention in recent years, and is widely disseminated worldwide. It exhibits excellent antioxidant and immunomodulatory potential and has been known for a long time by the Chinese. Due to its characteristics, it has been denominated as a 'miracle fruit', 'super fruit' or 'super food' because it is part of a group of red fruits that have in their composition several secondary metabolites, among them flavonoids, along with bioactive effects. Flavonoids are one of the compounds responsible for the characteristic pigmentation found in fruits and vegetables and protect the body against oxidative damage (Jamin, 2009; Reeve et al., 2010; Karp, 2012; Silva, Degáspari, 2014; Donno et al., 2015).

Reeve et al. (2010) evaluated the potential of orally consuming GB juice to alter the sun damage caused to the skin by ultraviolet (UV) radiation. This evaluation was conducted in rats. The results showed that juice consumption at $5 \%$ was able to promote oedema reduction due to sunburn. In addition, the juice was able to protect against immunosuppression promoted by UV radiation.

Zhao and Bojanowski (2015) described the dermatological uses of Lycium barbarum. These authors found that, although this fruit is a strong candidate for dermatological use, few publications report its use. Some previously reported effects include antioxidant, antiinflammatory and immunomodulatory activities (Zhao, Bojanowski, 2015). However, no publications exist in the literature about a nanostructured system containing this extract.

Thus, this study assessed the incorporation of a GB extract into a structured cosmetic system aiming to optimise its transport through the skin. Highly organised systems are more suitable than conventional cosmetic systems, since, due to the highly structural organisation of the formulation, they have greater stability (Chiari et al., 2012a). Here, we report the design and characterisation of structured liquid crystalline cosmetic formulation incorporated with GB extract with antioxidant activity aimed at the future topical treatment or prevention of skin disorders associated with ageing.

\section{MATERIAL AND METHODS}

\section{Goji berry extract preparation}

Dehydrated fruits of goji berry were purchased in the market of Leme city, São Paulo, Brazil in November 2015.

After being selected, $130 \mathrm{~g}$ of fruits was weighed and macerated in $96 \%(\mathrm{v} / \mathrm{v})$ ethanol solution for 2 days at room temperature. After this period, the extract was separated and another $200 \mathrm{~mL}$ of the same solvent was added to the fruits for a new extraction period (remaceration). This cycle was maintained for 14 days. The total volume of solvent used was $1000 \mathrm{~mL}$.

The obtained extract was stored in an amber glass bottle at $5 \pm 2{ }^{\circ} \mathrm{C}$. At the end of the 14 days, the resulting filtrates were collected and evaporated with the aid of a rotavaporator at $60 \pm 2{ }^{\circ} \mathrm{C}$ until complete elimination of the organic solvent (ethanol), thereby obtaining the goji berry soft extract (Cui et al., 2011; Pai et al., 2013).

The goji berry soft extract was packed in an amber glass vial and stored at $-5 \pm 2{ }^{\circ} \mathrm{C}$ until use.

\section{Measurement of the antioxidant activity}

The assessment of the antioxidant activity of GB extract was performed using the 1,1-diphenyl2-picrylhydrazyl radical (DPPH) assay, according to methodology described by Mensor et al. (2001) and Falcão et al. (2006), modified by Chiari et al. (2012b).

One millilitre of the extract aqueous solution at various concentrations was added to $2.5 \mathrm{~mL}$ of DPPH methanolic solution $(0.004 \%)$. The solutions were kept out of the light and after 30 minutes the absorbance of the solutions was determined at $515 \mathrm{~nm}$.

Control solutions containing only $1 \mathrm{~mL}$ of water and $2.5 \mathrm{~mL}$ of the $0.004 \%$ methanolic solution of DPPH were used. The mean absorbance of these samples was used as the maximum absorbance, which was used to calculate the inhibition percentage (\% DPPH inhibition) of the DPPH radical (Molyneux, 2004).

$\%$ DPPH inhibition $=\frac{(\mathrm{A} \max -\mathrm{A} \text { test })}{\mathrm{A} \max } x 100$,

Amax is the absorbance of DPPH at $515 \mathrm{~nm}$ in the absence of sample (control).

Atest is the absorbance of DPPH at $515 \mathrm{~nm}$ in the presence of sample.

The DPPH assay was performed in triplicate. 


\section{Design of the cosmetic formulation}

For the formulation design, an extensive search was made in the literature regarding raw materials that favour the permeation of active principles (permeation promoters) in order to ensure the penetration of the GB extract through the stratum corneum.

After designing the composition of the formulations (Table I), they were prepared by the conventional technique of emulsions preparation. For this, the aqueous and oily phases were separately heated to $75^{\circ} \mathrm{C}$ for further mixing and vigorous stirring until cooling. In the formulation containing GB extract, the soft extract was solubilised in $10 \%$ of the water (discounted from the total water content of the formulation). Right after preparation and cooling, the extract solution was mixed with vigorous agitation (Cefali et al., 2015).

\section{Measurement of the formulation antioxidant activity}

This assay was performed with the same methodology as for the assessment of the antioxidant activity of the GB extract, but using as samples the formulation containing the extract. Thus, $0.5 \mathrm{~g}$ of the emulsion containing the GB soft extract was weighed and solubilised in $0.5 \mathrm{~mL}$ of ethanol. To the DPPH solution, $0.3 \%$ Tween-20 was added to facilitate dispersion of the formulation and to prevent turbidity. After the addition of $2.5 \mathrm{~mL}$ of the DPPH solution, a spectrophotometer reading was performed at $515 \mathrm{~nm}$ after 30 minutes of the reaction. As a negative control, the base formulation (not containing the GB extract) was used, to assess interference from any raw material in the emulsion. Thus, the Amax used in the calculation of $\%$ of DPPH inhibition was the absorbance of the reaction with the DPPH solution and base formulation solubilised in ethanol $(0.5 \mathrm{~g}$ of base formulation solubilised in $0.5 \mathrm{~mL}$ of ethanol) (Cefali et al., 2015).

\section{Analysis of the preliminary stability of the cosmetic formulation}

The organoleptic characteristics (colour, odour and appearance), in addition to the $\mathrm{pH}$ values and relative density of the formulation, were monitored during a period of 30 days, keeping the samples at room temperature $\left(24 \pm 2{ }^{\circ} \mathrm{C}\right)$, at $38 \pm 2{ }^{\circ} \mathrm{C}$ and at $4 \pm 2{ }^{\circ} \mathrm{C}$, to assess formulation stability (Brazil, 2004; Isaac et al., 2008).

The $\mathrm{pH}$ was measured using a digital $\mathrm{pH}$ meter. For this, dispersions (10\% in deionised water) of the formulation were prepared (Davis, 1977).

The relative density was measured with the aid of a pycnometer. For this, the mass of the empty pycnometer, of the pycnometer with water and of the pycnometer with the formulation was determined. The mass of the product contained in the pycnometer volume was divided by the mass of the water contained in the same volume (Brazil, 2004; Isaac et al., 2008).

These determinations were performed 24 hours after the preparation of the emulsion (day 0 ) and after 7, 15 and 30 days (Brasil, 2004).

TABLE I - Percent composition (w/w) of test emulsions 1, 2 and 3

\begin{tabular}{lccc}
\hline Raw material (INCI name) & $\begin{array}{c}\text { Test } \\
\text { formulation 1 }\end{array}$ & $\begin{array}{c}\text { Test } \\
\text { formulation 2 }\end{array}$ & $\begin{array}{c}\text { Test } \\
\text { formulation 3 }\end{array}$ \\
\hline Cetyl alcohol & 5.00 & 3.00 & 3.00 \\
Grape seed oil & - & - & 3.00 \\
Shea butter & 2.00 & 2.00 & - \\
Emulsifyin wax NF & 8.00 & 5.00 & 5.00 \\
(Polawax NF $^{\circledR}$ ) & & & \\
Cetearyl alcohol & 0.50 & 0.50 & 0.50 \\
Phenoxyethanol (and) Methylparaben (and) Ethylparaben (and) & 0.50 & 0.50 & 0.50 \\
Propylparaben (and) Butylparaben (and) Isobutylparaben (Phenonip ${ }^{\circledR}$ ) & & & \\
BHT & 0.05 & 0.05 & 0.05 \\
Disodium EDTA & 0.01 & 0.01 & 0.01 \\
Glicerin & 5.00 & 5.00 & 5.00 \\
Ammonium Acryloyldimethyltaurate/VP Copolymer (Aristoflex ${ }^{\circledR}$ AVC) & 1.00 & 1.00 & 1.00 \\
Water & q.s.p. $100.00 \mathrm{~g}$ & q.s.p. $100.00 \mathrm{~g}$ & q.s.p. $100.00 \mathrm{~g}$ \\
\hline
\end{tabular}




\section{Rheological characterisation of the formulations}

For the characterisation of the formulations (containing or not the GB extract) regarding the flow behaviour and spreadability, rheology was employed. For this, an AR2000ex rheometer was used. The assays were conducted with cone-plate type sensor $\left(2^{\circ}\right.$ angulation and $52 \mathrm{~mm}$ gap) and data were analysed by Rheology Advantage Data Analysis software. The assays were conducted in duplicate.

The rheological behaviour was evaluated by determining:

- The flow property of the samples, with shear stress of $0-100 \mathrm{~Pa}$ for a period of 120 seconds for the ascending curve and shear stress of 100-0 $\mathrm{Pa}$ for 120 seconds for the descending curve;

- A stress sweep by subjecting samples to a constant frequency of $1 \mathrm{~Hz}$ using variable shear stresses of 0.1 to $10 \mathrm{~Pa}$.

- A frequency sweep by subjecting samples to a constant shear stress of $1 \mathrm{~Pa}$, using variable frequencies from 0.1 to $50 \mathrm{~Hz}$.

- A creep and recovery assay, subjecting samples to a shear stress of $1 \mathrm{~Pa}$ for 200 seconds. Then, the stress was removed and the behaviour of the sample was followed for another 200 seconds (Isaac et al., 2013b).

All the tests were performed at a temperature of $25 \pm 1{ }^{\circ} \mathrm{C}$, with the formulations also kept at room temperature. The graphs were plotted in the software Origin 7.0.

\section{Assessment of the formulations using small angle $\mathrm{X}$-ray scattering (SAXS)}

The nanostructures of the phases that compose the base formulation and the formulation containing the GB extract were assessed using small angle X-ray scattering (SAXS) measurements.

Data collection was performed at the National Synchrotron Light Laboratory (Laboratório Nacional de Luz Síncroton LNLS in Campinas), using the synchroton light line for SAXS, equipped with a monochromator $(\lambda=1.608 \mathrm{~A}) \mathrm{Si}\left(\begin{array}{lll}1 & 1 & 1\end{array}\right)$ that produces a horizontally focused beam of light. A vertical X-ray detector and a multichannel analyser were used to capture the intensity of the radiation scattered by the samples, I (q), as a function of the scattering vector modulus $\mathrm{q}, \mathrm{q}=(4 \pi / \lambda) \sin (\varepsilon / 2)$, with $\varepsilon$ as the scattering angle. The dispersion of the rays produced by the slits was subtracted from the total scattering intensity. Both intensities are described in relative units, but for a quantitative comparison, they were normalised to the same experimental conditions (Manaia et al., 2012).

\section{Evaluation of formulations using polarised light microscopy}

Samples of the formulation containing or not the GB extract were arranged under slides and coverslips, and were then observed under a polarised light microscope (Carl Zeiss Axioskop-40). The magnification used was 400x (Manaia et al., 2012).

\section{Analysis of the bioadhesion force}

The bioadhesion strength of the formulations was analysed using a TAXT plus texture analyser (Stable Micro Systems $\left.{ }^{\circledR}\right)$. Samples of the formulation containing or not the GB extract were analysed and a commercial anti-ageing formulation (Vitanol- $\mathrm{A}^{\circledR}$ ) as the standard. This standard was chosen due to its similar characteristics to the formulation investigated in the study, i.e. it is an antiageing emulsion intended for facial skin care (OshiroJr et al., 2015; Oshiro et al., 2018).

Dissected porcine ear skin was obtained from a slaughterhouse and dermatomed was used as a biological substrate at a thickness of $500 \mu \mathrm{m}$. Prior to the test, hair was removed with a pair of scissors and then adhered to the probe.

The sample to be assessed was previously packed in a cylindrical and shallow plastic bottle $(2 \mathrm{~cm}$ in diameter and $1 \mathrm{~cm}$ high) that was placed under the probe. Thereafter, the lowering of the probe was run at a rate of $1 \mathrm{~mm} / \mathrm{s}$ until the pig ear skin, adhered to the probe, came into contact with the surface of the formulation. Instantly, a downward force of $0.05 \mathrm{~N}$ was applied for a set time $(30 \mathrm{~s})$ to ensure intimate contact between the sample and the substrate. After this time, the probe was removed at a speed of $1 \mathrm{~mm} / \mathrm{s}$ and, the force required to remove the substrate from the formulation surface was determined as the resultant force versus time. Assays were repeated five times. Data were compared using one-way ANOVA and Tukey's multiple comparison test $(\mathrm{p}<0.05)$.

\section{RESULTS AND DISCUSSION}

\section{Goji berry extract preparation}

The GB soft extract was obtained by the maceration method, with the extractive solvent renewed every two days the (re-maceration) (Sajjadi et al., 2016; Das Dores et al., 2017). This practice aimed to avoid solvent 
saturation, allowing the maximum extraction rate of the components of interest from the dehydrated fruits. Maceration, according to Timaco (2012), is capable of promoting the extraction of important substances such as phenolic compounds, polysaccharides and mineral elements.

After extract rotavaporation, $90 \mathrm{~mL}$ of soft $\mathrm{GB}$ extract with a dark yellow colour was obtained.

\section{Measurement of the antioxidant activity}

In order to assess the antioxidant activity, the GB soft extract in various concentrations was added to a $0.004 \%$ solution of DPPH, obtaining a colour variation that was measured spectrophotometrically, ranging from purple to yellow. After reading in a spectrophotometer at $515 \mathrm{~nm}$, the results were plotted and are shown in Figure 1.

As seen in Figure 1, the antioxidant activity of the GB soft extract was proportional to its concentration. This was represented by the equation $y=-93.185 x^{2}+185.88 x+0.1671$, which describes, through polynomial regression, the relationship between the extract concentration and the percentage of free radical inhibition. By means of this equation, the $\mathrm{IC}_{50}$ value of the GB soft extract was calculated, which in this case corresponded to $0.32 \%$ of the extract in solution. The $\mathrm{IC}_{50}$ is the concentration capable of inhibiting $50 \%$ of the free radicals present in the evaluated solution (Chiari et al., 2012b).

This result aided in determining the concentration of GB soft extract to be added to the base formulation. Considering that $1 \%$ of the extract promotes approximately $100 \%$ inhibition of the DPPH radical, this concentration was multiplied by 2 for addition to the base emulsion, thus $2 \%$ was used (an approximately concentration). The reason for doubling the concentration capable of inhibiting $100 \%$ of free radicals is the fact that the skin acts as a barrier to the penetration of the active compounds. Thus, using a higher concentration than that required is a useful way to increase the available concentration in the epidermis and dermis, since the penetration rate will never be equal to $100 \%$ (Idson, 1971). Increasing the drug concentration in topical formulations to improve efficacy has been used in recent studies (Anand, Blay, 2011).

\section{Design of the cosmetic formulation}

For the design of a structured cosmetic formulation, raw materials that favour the penetration of the active substance through the skin were chosen; these raw materials are known as permeation enhancers. The aim

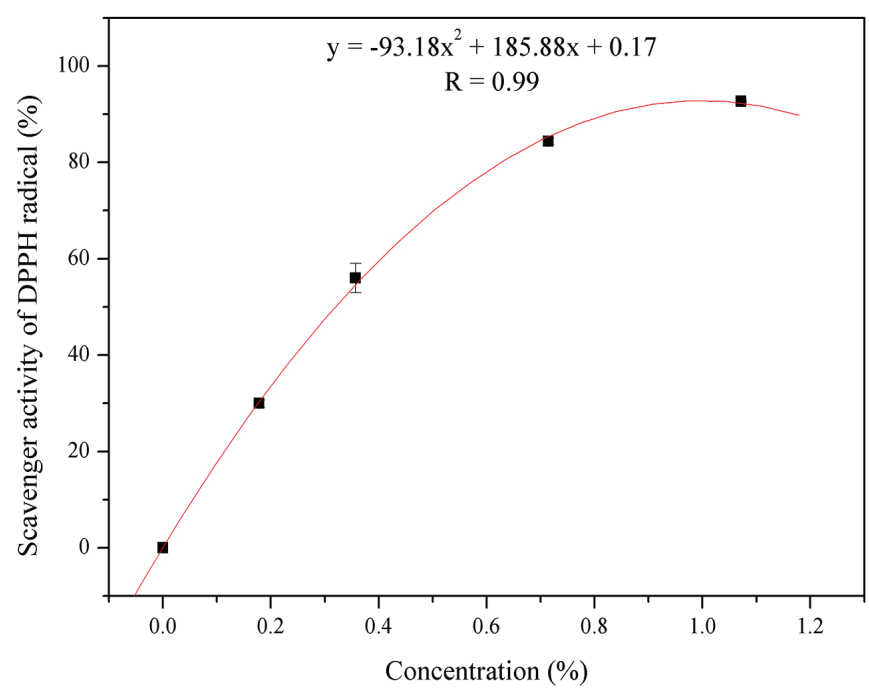

FIGURE 1 - Inhibition percentage of the DPPH radical versus concentration of the GB soft extract.

was to ensure that the antioxidant GB soft extract could be able, if applied to the skin, to reach both the epidermis and the dermis. According to Martins and Veiga (2002), permeation enhancers are compounds that can permeate or interact with stratum corneum constituents, when incorporated into a transdermal formulation, but do not possess pharmacological activity, but merely reduce skin resistance to drug diffusion. In this case, the surfactants and humectants used in the formulation can be cited.

A base formulation (test formulation 1) was proposed and, from this, two other formulations (test formulations 2 and 3 ) were prepared by altering the raw materials and their respective concentrations (Table I). The test formulations were macroscopically analysed for viscosity and spreadability. Emulsions 1 and 2 did not disperse the self-emulsifying wax completely, leaving them with a rough appearance and the presence of lumps. Considering this, test formulation 3 was considered most suitable due to its lower viscosity, a characteristic considered excessive in the other formulations, as well as a more pleasant sensorial aspect.

\section{Measurement of the antioxidant activity of the formulation}

The antioxidant activity of the formulation containing the GB soft extract was evaluated. The inhibition percentage of DPPH radicals obtained using $0.5 \mathrm{~g}$ of the formulation in the reaction was $20.16 \pm 10.34 \%$. Considering that $0.5 \mathrm{~g}$ of the formulation were dispersed in $3.5 \mathrm{~mL}$ for the reaction with the DPPH radical, a final concentration of $0.14 \mathrm{~g}$ of emulsion $/ \mathrm{mL}$ was obtained during the reaction. Thus, each $0.14 \mathrm{~g}$ of 
emulsion containing the GB soft extract per millilitre was capable of inhibiting approximately $20 \%$ of the free radicals in the reaction.

Cefali et al. (2015) evaluated a phytocosmetic containing lycopene; the percentage inhibition of DPPH radicals was $19.51 \%(0.1 \mathrm{~g} / \mathrm{mL})$. The authors reported the antioxidant effect to avoid skin ageing, considering daily use and accumulation of the product on the skin. Also, it should be emphasised that daily application of the product on the face would probably exceed a mass of $0.14 \mathrm{~g}$, reinforcing the anti-ageing potential of the formulation.

\section{Analysis of the preliminary stability of the cosmetic formulation}

\section{Assessment of the organoleptic characteristics}

The assessment of the organoleptic characteristics, i.e. colour, odour and appearance, is important to follow the changes in these characteristics over time, which is an indicative of stability of the formulation (Isaac et al., 2008).

During the 30-day stability evaluation, macroscopic analyses were performed, i.e. the samples were visually observed for their appearance, relating them to the reference sample, understood as the formulation at the time of preparation. The sample maintained at room temperature could also be considered as a control, since there was no acceleration of instabilities due to temperature and/or light radiation. The odour and colour of the formulations were also evaluated.

On the day of preparation, the formulations without GB extract and with GB extract had similar but not identical characteristics. The formulation without GB extract was white in colour, with a characteristic odour and homogeneous emulsion appearance. The formulation with GB soft extract presented a slightly yellowish colour, with the characteristic odour of the extract and the appearance of a homogeneous emulsion.
After 30 days, it was possible to observe that the formulations with and without the GB extract were stable, as no changes were observed in its appearance (no gas formation or phase separation), odour or colour. The same behaviour was observed after storage at room temperature, $38^{\circ} \mathrm{C}$ and $4{ }^{\circ} \mathrm{C}$ for a period of 30 days.

\section{Determination of $\mathrm{pH}$}

The $\mathrm{pH}$ values of the formulations containing or not the GB soft extract were monitored for 30 days are shown in Tables II and III.

Analysing the data presented in Tables II and III, it can be observed that the emulsions did not present significant differences in $\mathrm{pH}$ with the passage of time. According to Friedrich et al. (2007), this shows that even with changes in temperature and luminosity, there was no degradation of the fatty compounds. The $\mathrm{pH}$ values remained within the recommended range for cosmetic products, varying approximately between 5 and 6.5 . Vieira et al. (2009) considered that $\mathrm{pH}$ variations greater than 15 should be investigated. In the formulations investigated here, with or without the presence of the GB soft extract, the maximum variation between $\mathrm{t} 0$ and $\mathrm{t} 30$ was $9.24 \%$.

The determination of the $\mathrm{pH}$ of cosmetic formulations is of extreme importance as it should be a value compatible with that of the region of the body in which it will be applied. According to Leonardi et al. (2002), the skin has a slightly acidic $\mathrm{pH}$, ranging from 4.8 to 5.8 , which favours the bactericidal and fungicidal protection of the skin surface. It is noteworthy that skin secretions have an important buffering capacity, since the $\mathrm{pH}$ of the skin can be altered as a result of the use of topical products.

It was determined that the $\mathrm{pH}$ values obtained in this study were satisfactory since they presented values between 5.19 and 6.22 , indicating slightly acidic characteristics. The formulation with GB was slightly more acidic than the base formulation, which suggests that the extract also has acidic characteristics.

TABLE II - $\mathrm{pH}$ values determined during 30 days in the formulation without the GB soft extract (mean \pm standard deviation). The percentage of variation comparing t0 and $\mathrm{t} 30$ is shown

\begin{tabular}{|c|c|c|c|}
\hline Time (days) & $24 \pm 2{ }^{\circ} \mathrm{C}$ & $38 \pm 2^{\circ} \mathrm{C}$ & $4 \pm 2^{\circ} \mathrm{C}$ \\
\hline 0 & $5.34 \pm 0.27$ & $5.34 \pm 0.27$ & $5.34 \pm 0.27$ \\
\hline 7 & $6.22 \pm 0.12$ & $6.12 \pm 0.11$ & $6.16 \pm 0.26$ \\
\hline 15 & $5.83 \pm 0.09$ & $6.01 \pm 0.10$ & $5.23 \pm 0.16$ \\
\hline 30 & $5.80 \pm 0.10$ & $5.70 \pm 0.17$ & $5.83 \pm 0.15$ \\
\hline $\begin{array}{l}\text { \%variation } \\
\text { (comparing t0 and t } 30 \text { ) }\end{array}$ & 8.61 & 6.74 & 9.24 \\
\hline
\end{tabular}


TABLE III - pH values determined during 30 days in the formulation with GB soft extract (mean \pm standard deviation). The percentage of variation comparing t 0 and $\mathrm{t} 30$ is shown

\begin{tabular}{lccc}
\hline Time (days) & $24 \pm 2{ }^{\circ} \mathrm{C}$ & $38 \pm 2{ }^{\circ} \mathrm{C}$ & $4 \pm 2{ }^{\circ} \mathrm{C}$ \\
\hline 0 & $5.84 \pm 0.05$ & $5.84 \pm 0.05$ & $5.84 \pm 0.05$ \\
7 & $5.64 \pm 0.47$ & $5.20 \pm 0.14$ & $5.25 \pm 0.08$ \\
15 & $5.72 \pm 0.14$ & $5.42 \pm 0.18$ & $5.23 \pm 0.14$ \\
30 & $5.63 \pm 0.15$ & $5.40 \pm 0.26$ & $5.67 \pm 0.40$ \\
\%variation & 3.48 & 7.48 & 2.91 \\
(comparing t0 and t30) & & & \\
\hline
\end{tabular}

Determination of the relative density

Physicochemical tests are important for the investigation of structural alterations of the formulation that are not visually perceptible, i.e. the relative density. The values of the formulations assessed over 30 days of analysis are shown in Tables IV and V.

The emulsions with and without GB extract did not show relative density variations during the 30 -day stability study, when the samples were stored at room temperature, $38 \pm 2{ }^{\circ} \mathrm{C}$ and $4 \pm 2{ }^{\circ} \mathrm{C}$, with a relative density value close to $1.0 \mathrm{~g} / \mathrm{cm}^{3}$. Density values are important for semi-solid products according to the Cosmetic Products Stability Guide, as they may indicate the incorporation of air or the loss of volatile ingredients. This also happens with water, which can cause an increase in the viscosity of the formulation. However, this apparently did not occur in this study.

\section{Rheological characterisation of the formulations}

The rheological characterisation was performed for both the base formulation and the formulation containing the GB soft extract. Besides characterising the formulations, this allowed us to evaluate if the addition of the GB soft extract induced significant changes to the formulation's structure.

The first assay performed was the flow analysis of the formulations (Figure 2). Both exhibited HerschelBulkley behaviour, since there was a yield value, followed by a decrease in viscosity with an increase in shear.

TABLE IV - Relative density values $\left(\mathrm{g} / \mathrm{cm}^{3}\right)$ measured periodically, for 30 days, for the base formulation (mean \pm standard deviation). The percentage of variation comparing t 0 and $\mathrm{t} 30$ is shown

\begin{tabular}{lccc}
\hline Time (days) & $\mathbf{2 4 \pm \mathbf { 2 } ^ { \mathbf { } } \mathbf { C }}$ & $\mathbf{3 8} \pm \mathbf{2}^{\mathbf{0}} \mathbf{C}$ & $\mathbf{4} \pm \mathbf{2}^{\mathbf{0}} \mathbf{C}$ \\
\hline 0 & $0.977 \pm 0.006$ & $0.977 \pm 0.006$ & $0.977 \pm 0.006$ \\
7 & $0.977 \pm 0.012$ & $0.987 \pm 0.006$ & $0.983 \pm 0.012$ \\
15 & $0.987 \pm 0.006$ & $0.983 \pm 0.012$ & $0.987 \pm 0.006$ \\
30 & $0.987 \pm 0.006$ & $0.987 \pm 0.006$ & $0.987 \pm 0.006$ \\
\%variation & 0.989 & 0.989 & 0.989 \\
(comparing t0 and t30) & & & \\
\hline
\end{tabular}

TABLE V - Relative density values $\left(\mathrm{g} / \mathrm{cm}^{3}\right)$ measured periodically, for 30 days, for the formulation containing GB extract (mean \pm standard deviation). The percentage of variation comparing t0 and $\mathrm{t} 30$ is shown

\begin{tabular}{lccc}
\hline Time (days) & $\mathbf{2 4 \pm \mathbf { 2 } ^ { \mathbf { } } \mathbf { C }}$ & $\mathbf{3 8} \pm \mathbf{2}{ }^{\mathbf{}} \mathbf{C}$ & $\mathbf{4} \pm \mathbf{2}^{\mathbf{}} \mathbf{C}$ \\
\hline 0 & $0.967 \pm 0.006$ & $0.967 \pm 0.006$ & $0.967 \pm 0.006$ \\
7 & $0.977 \pm 0.006$ & $0.983 \pm 0.006$ & $0.967 \pm 0.006$ \\
15 & $0.973 \pm 0.012$ & $0.973 \pm 0.006$ & $0.983 \pm 0.006$ \\
30 & $0.987 \pm 0.006$ & $0.987 \pm 0.006$ & $0.977 \pm 0.006$ \\
\%variation & 2.034 & 2.034 & 0.997 \\
(comparing t0 and t30) & & & \\
\hline
\end{tabular}


The formulations exhibited low thixotropy, which is a favourable feature, since it is related to the spreadability of the preparation (Morais et al., 2005). It was also possible to demonstrate that the addition of the fluid GB extract promoted a slight reduction in the viscosity of the formulation. There was also an increase in thixotropy, favouring the spreadability of the formulation.

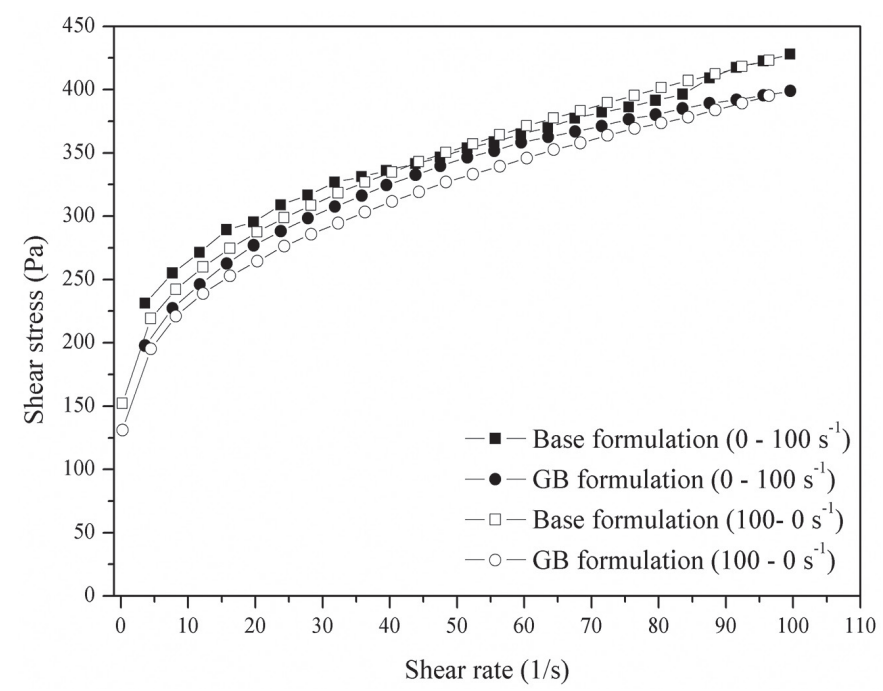

FIGURE 2 - Flow curve of the formulations containing or not the GB soft extract.

Shear stress (Figure 3 ) is an assay employed to verify the range of shear stress where a linear viscoelasticity region is found. For both formulations, the linear region of viscoelasticity occurred practically in the entire shear stress range evaluated, with 1 Pascal being the value determined for the continuation of the studies. A frequency sweep, on the other hand, allows for the analysis of the elastic ( $\left.G^{\prime}\right)$ and viscous (G”) moduli (Figure 4). The GB and base formulations presented a higher elastic modulus than viscous modulus, which was considered indicative of stability for emulsified formulations (Chiari et al., 2012a; Isaac et al., 2013a, b). However, the addition of the GB soft extract reduced the G' and G' values, which can be explained by the reduction in the relative fatty content of the formulation.

The results of the rheological characterisation, including the creep and recovery tests (Figure 5), showed a small reduction in viscosity and elastic modulus, interfering with the deformation (time from 0 to $200 \mathrm{~s}$ ) and recovery of the formulation (time from 200 to $400 \mathrm{~s}$ ).

\section{Assessment of the formulations by SAXS}

The SAXS technique is fundamental to confirm the presence of structures shown by polarised light microscopy (Figure 6). Well-defined peaks, known as

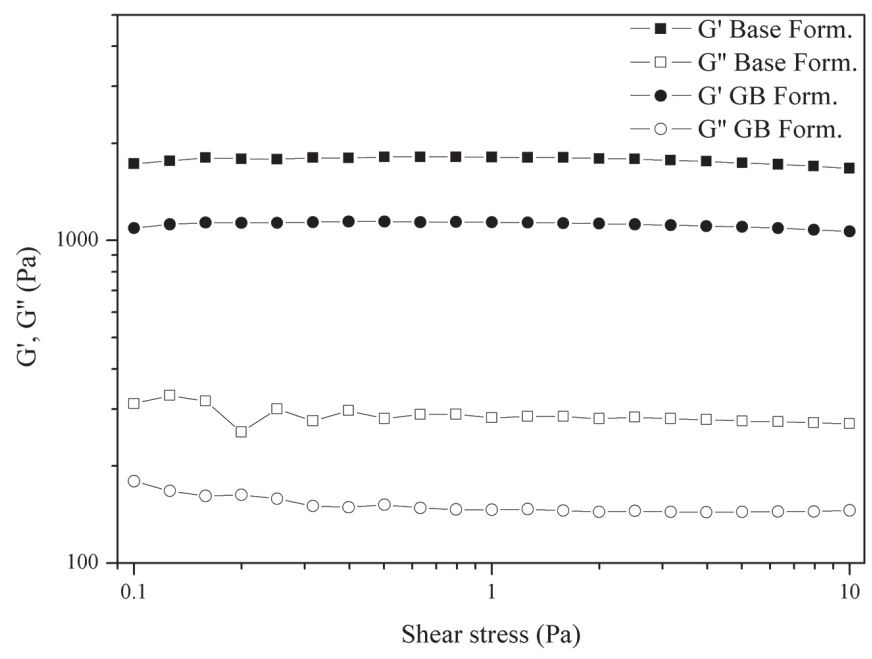

FIGURE 3 - Shear stress of the formulations containing or not the GB soft extract.

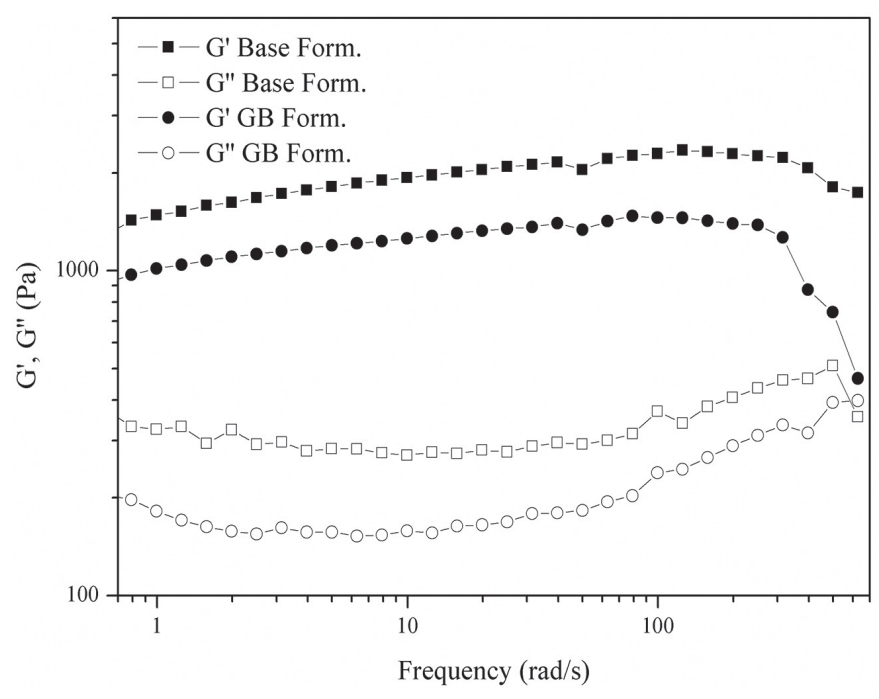

FIGURE 4 - Frequency sweep of the formulations containing or not the GB soft extract.

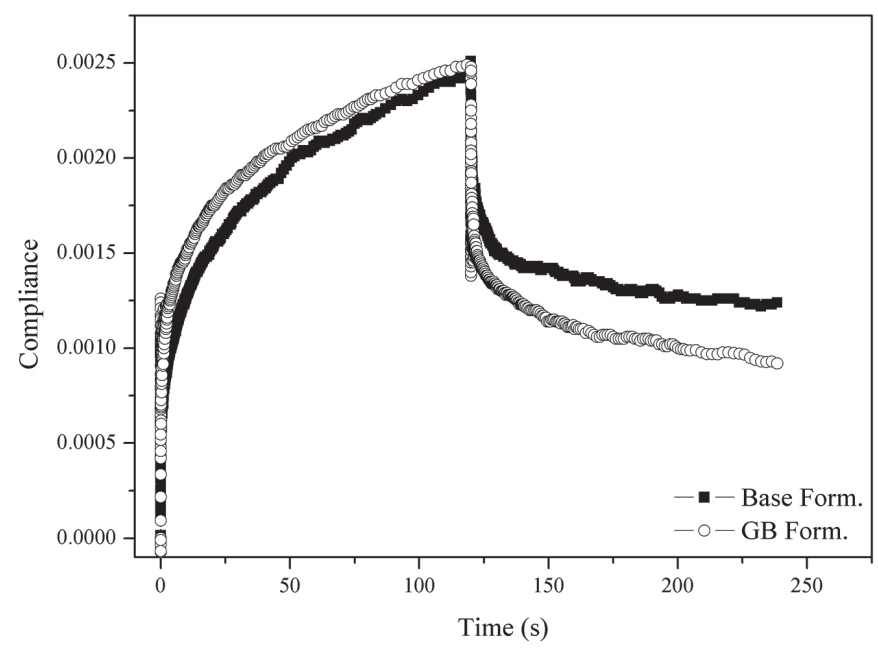

FIGURE 5 - Creep and recovery analysis of the formulations containing or not the GB soft extract. 
Bragg peaks, have been found in the analysis of similar formulations, revealing the presence of highly organised structures, such as liquid crystals (Ferreira et al., 2015). At medium to high concentrations of amphiphilic molecules such as surfactants, the systems are more structured than those at low concentrations. The amphiphilic molecules aggregate and form small, randomLy oriented crystalline domains, with lattices exhibiting 1D, 2D or 3D long range correlations.

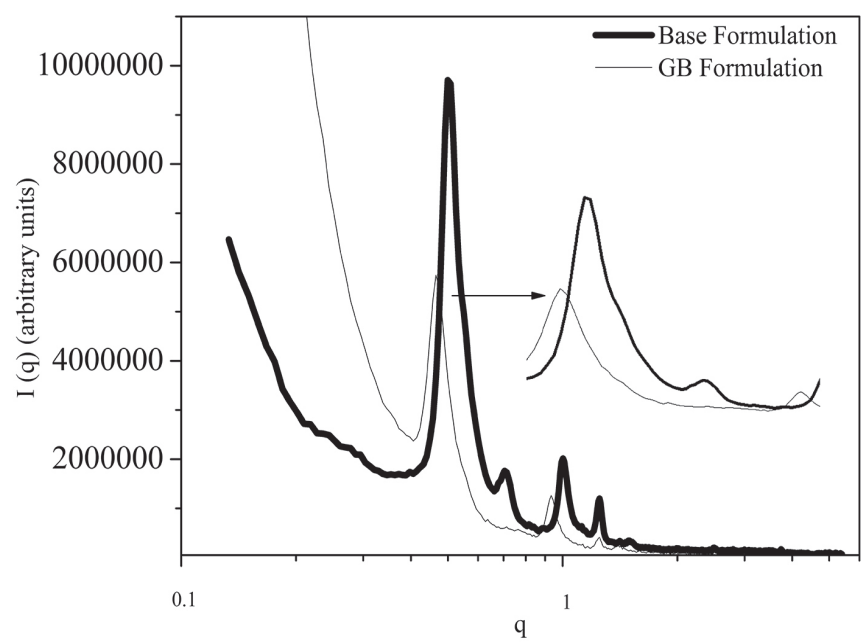

FIGURE 6 - SAXS assay results for the formulations containing or not the GB soft extract ( $\mathrm{q}$ was determined in $1 / \AA$ ). A zoom of the image is indicate with the arrow.

The SAXS curves for these formulations exhibited sharp maxima (or Bragg peaks) for specific values of the modulus of the scattering vector q. The scattering technique can now be called SAXD. If the SAXD patterns contain several peaks, their positions on the q axis reveal the type of crystal lattice of the structures and permit their lattice parameters to be calculated (Klug, Alexander, 1954). The relationship between the positions of these peaks on the q-axis indicates the crystalline structure type and allows structural parameters to be calculated (Klug, Alexander, 1954). The d parameter was calculated as $2 \pi$ /qmax, where qmax is the maximum intensity value of the scattering vector peak (Manaia et al., 2015).

These analyses indicated the formation of lamellar phase liquid crystals, and thus the high structural organisation of the formulation was shown, indicating the stability of the system.

\section{Evaluation of the formulations using polarised light microscopy}

Polarised light microscopy is a simple technique that can be used to show anisotropic liquid-crystalline structures, such as liquid crystals (Müller-Goymann, 2004). The presence of these highly organised systems (Figure 7) in emulsified formulations indicates excellent stability of the system (Chiari et al., 2012a). In this case, the presence of anisotropic structures was observed, probably around the droplets of the internal phase of the emulsion.
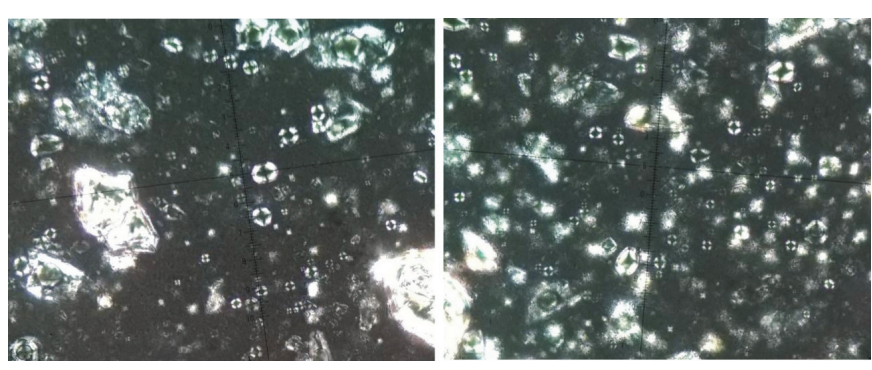

FIGURE 7 - Photomicrographs of the formulations not containing (left) and containing (right) GB soft extract.

\section{Analysis of the bioadhesion force}

In formulations for skin application, such as creams, ointments, solutions and lotions, considering a prolonged therapeutic effect is extremely difficult as external factors such as humidity, temperature and movements remove them easily. Thus, in order to evaluate the bioadhesive capacity of the formulation with a biological substrate, the adhesion strength was evaluated (Table VI). A commercial anti-ageing emulsion formulation was used as a control (Oshiro-Jr et al., 2015; Oshiro et al., 2018).

TABLE VI - Adhesion strength values (Wad) for the formulations containing or not the GB soft extract. The results are expressed as mean and standard deviation, $n=5$ replicates

\begin{tabular}{ll}
\hline Formulation & $\begin{array}{c}\text { Adhesion strength } \\
\text { values }\left(\mathbf{W}_{\mathrm{ad}}\right)\end{array}$ \\
\hline Base formulation & $0.073^{\mathrm{a}} \pm 6.14$ \\
Formulation with GB soft extract & $0.046^{\mathrm{b}} \pm 6.59$ \\
Vitanol-A $^{\circledR}$ & $0.049^{\mathrm{b}} \pm 4.28$ \\
\hline
\end{tabular}

a,b Different letters indicate statistically different values $(\mathrm{p}<0.05)$.

The formulation without the addition of GB extract showed a higher bioadhesion value when compared to the formulation containing GB. This can be explained by the viscosity of the formulation, since formulations with higher viscosity tend to exhibit greater adhesion strength (Oshiro-Jr et al., 2015). The reduction in viscosity was a result of the addition of the GB soft extract. These results corroborate the results observed in the rheology measurements. However, despite the decrease in adhesion 
strength, when compared to the commercial formulation, the formulation containing the GB soft extract had a statistically equal adhesion strength, which allowed us to infer the suitability of the developed formulation. Adhesion strength tests have relevance in pharmaceutical formulations since higher values of bioadhesion may prolong the duration of action and absorption of the drug, thus improving the clinical performance of the formulation.

In conclusion, the combination of raw materials chosen in the studied formulation has the potential to provide a cosmetic with a lamellar phase. It showed adequate organoleptic characteristics and remained stable when the GB soft extract was incorporated. It also exhibited suitable bioadhesive properties on the skin, even when compared to a commercial formulation containing tretinoin. The antioxidant activity of the GB extract was also shown. Thus, this study demonstrates the suitability of applying GB extract as an anti-ageing cosmetic using this formulation.

\section{ACKNOWLEDGMENT}

Coordenação de Aperfeiçoamento de Pessoal de Nível Superior - Brasil (CAPES) - Finance Code 001. Laboratório Nacional de Luz Síncrotron (LNLS- SAXS1).

\section{REFERENCES}

Alchorne MMA, Abreu MAMM. Dermatologia na pele negra. An Bras Dermatol. 2008;83(1):7-20.

Anand P, Bley K. Topical capsaicin for pain management: therapeutic potential and mechanisms of action of the new high-concentration capsaicin $8 \%$ patch. Br J Anaesth. 2011;107(4):490-502.

Batistela MA, Chorilli M, Leonardi GR. Abordagens no estudo do envelhecimento cutâneo em diferentes etnias. Rev Bras Farm. 2007;2(88):59-62.

Bianchi MLP, Antunes LMG. Radicais livres e os principais antioxidantes da dieta. Rev Nutr. 1999;12(2):123-30.

Brasil. Ministério da Saúde. Agência Nacional de Vigilância Sanitária. Guia de estabilidade de produtos cosméticos. 2004. [Cited 2017 March 6] Available from: http://www.anvisa.gov. br/divulga/public/series/cosmeticos.pdf.
Cefali LC, Souza-Moreira TM, Corrêa MA, Salgado HRN, Isaac VLB. Development and evaluation of an emulsion containing lycopene for combating acceleration of skin aging. Braz J Pharm Sci. 2015,51(3):579-90.

Chiari BG, Almeida MGJ, Correa MA, Isaac VLB. Cosmetics quality control. In: Akyar I, editor. Latest research into quality control. London: InTech Open; 2012a. v.1, p.337-64.

Chiari BG, Severi JA, Pauli-Credendio PA, Sylos CM, Vilegas W, Corrêa MA, Isaac VLB. Assessment of the chemical profile, polyphenol content and antioxidant activity in extracts of Psidium guajava L. fruits. Int J Pharmacol Pharm Sci. 2012b;4(5):331-6.

Cui B, Liu S, Lin X, Wang J, Li S, Wang Q, Li S. Effects of Lycium barbarum aqueous and ethanol extracts on high-fatdiet induced oxidative stress in rat liver tissue. Molecules. 2011;16(11):9116-28.

Das Dores RGR, Souza CS, Xavier VF, Guimarães SF, Juliana CSAB, Braga TV. Antioxidant potential of fresh leaves of Motherwort herb (Leonurus sibiricus L.). PMIO 2017;4(S01):S1-S202.

Davis HM. Analysis of creams and lotion. In: Senzel AJ, editor. Newburguer's manual of cosmetic analysis. Washington: Association of Official Analytical Chemists; 1977. chap.4, p.32.

Degáspari $\mathrm{CH}$, Waszczynskyj N. Propriedades antioxidants de compostos fenólicos. Visão Acadêmica. 2004;5(1):33-40.

Donno D, Beccaro GL, Mellano MG, Cerutti AK, Bounous G. Goji berry fruit (Lycium spp.): antioxidant compound fingerprint and bioactivity evaluation. J Func Foods. 2015;18(pt B):1070-85.

Falcão DQ, Costa ER, Alviano DS, Alviano CS, Kuster RM, Menezes FS. Atividade antioxidante e antimicrobiana de Calceolaria chelidonioides Humb. Bonpl. \& Kunth. Rev Bras Farmacog. 2006;16(1):73-6.

Ferreira SG, Conceição VC, Gouveia NS, Santos GS, Santos RLC, Lira AAM, Cavalcanti SCH, Sarmento VHV, Nunes RS. An environmentally safe larvicide against Aedes aegypti based on in situ gelling nanostructured surfactant systems containing an essential oil. J Colloid Interface Sci. 2015;456:190-6. 
Friedrich M, Primo FT, Funck JAB, Laporta LV, Alves MP, Bittencourt CF, Escarrone ALV. Avaliação da estabilidade físicoquímica de creme não iônico inscrito no Formulário Nacional. Lat Am J Pharm. 2007, 26(4):558-562.

Hirata LL, Sato MEO, Santos CAM. Radicais livres e o envelhecimento cutâneo. Acta Farm Bonaerense. 2004;3(23):418-26.

Idson B. Biophysical factors in skin penetration. J Soc Cosmet Chem. 1971;22(10):615-34.

Isaac VLB, Cefali LC, Chiari BG, Almeida MGJ, Ribeiro HM, Correa MA. Effect of various thickening agents on the rheological properties of oil-in-water emulsions containing nonionic emulsifier. J Dispersion Sci Technol. 2013a;34(6):8805.

Isaac VLB, Cefali LC, Chiari BG, Oliveira CCLG, Salgado HRN, Corrêa MA. Protocolo para ensaios físico-químicos de estabilidade de fitocosméticos. Rev Ciênc Farm Bas Apl. 2008;1(88):81-96.

Isaac VLB, Moraes JDD, Chiari BG, Guglielmi DAS, Cefali LC, Rissi NC, Correa MA. Determination of the real influence of the addition of four thickening agents in creams using rheological measurements. J Dispersion Sci Technol. 2013b;34(4):532-8.

Jamin E. Superfruits: are they authentic? Fruit Processing. 2009;19(4):170-5.

Karp D. Frontiers of fruit in California: new and rediscovered fruit types with potential for commercial cultivation. J Am Pom Soc. 2012;66:125-32.

Klug HP, Alexander LE. X-ray diffraction procedures for polycrystalline and amorphous materials. New York: John Wiley; 1954. chap.1.

Leonardi GR, Gaspar LR, Campos PMBGM. Estudo da variação do $\mathrm{pH}$ da pele humana exposta à formulação cosmética acrescida ou não das vitaminas $\mathrm{A}, \mathrm{E}$ ou de ceramida, por metodologia não invasiva. An Bras Dermatol. 2002;77(5):563-9.

Manaia EB, Kaminski RCK, Oliveira AG, Corrêa MA, Chiavacci LA. Multifunction hexagonal liquid-crystal containing modified surface $\mathrm{TiO}_{2}$ nanoparticles and terpinen-4-ol for controlled release. Int J Nanomed. 2015;10:811-9.
Manaia EB, Kaminski RCK, Soares CP, Meneau F, Pulcinelli SH, Santilli CV, Chiavacci LA. Liquid crystalline formulations containing modified surface $\mathrm{TiO}_{2}$ nanoparticles obtained by sol-gel process. J Sol-Gel Sci Technol. 2012;63(2):251-257.

Martins MRFM, Veiga F. Promotores de permeação para a liberação transdérmica de fármacos: uma nova aplicação para as ciclodextrinas. Rev Bras Ciênc Farm. 2002;38(1):33-54.

Mensor LL, Menezes FS, Leitão GG, Reis AS, Santos TC, Coube CS, Leitão SG. Screening of Brazilian plant extracts for antioxidant activity by the use of DPPH free radical method. Phytother Res. 2001;15(2):127-30.

Molyneux P. The use of the stable free radical diphenylpicrylhydrazyl (DPPH) for estimating antioxidant activity. Songklanakarin J Sci Technol. 2004;26(2):211-9.

Morais GG, Santos ODH, Masson DS, Oliveira WP, Rocha Filho PA. Development of O/W emulsions with annato oil (Bixa orellana) containing liquid crystal. J Dispersion Sci Technol. 2005;26(5):591-6.

Müller-Goymann CC. Physicochemical characterization of colloidal drug delivery systems such as reverse micelles, vesicles, liquid crystals and nanoparticles for topical administration. Eur J Pharm Biopharm. 2004;58(2):343-56.

Oriá RB, Santana EN, Fernandes MR, Ferreira FVA, Brito GAC. Estudo das alterações relacionadas com a idade na pele humana, utilizando métodos de histo-morfometria e autofluorescência. An Bras Derm. 2003;78(4):425-43.

Oshiro-Junior JA, Carvalho FC, Soares CP, Chorilli MC, Chiavacci LA. Development of cutaneous bioadhesive UreasilPolyether hybrid films. Int J Polymer Sci. 2015;2015(art 727324):1-7.

Oshiro-Junior JA, Nasser NJ, Chiari-Andreo BG, Cuberes T, Chiavacci LA. Study of triamcionolone release and mucoadhesive properties of mesoporous hybrid films for oral disease treatment. Biomedical Physics \& Engineering Express. 2018 , in press.

Pai PG, Habeeba PU, Ullal S, Shoeb PA, Pradeepti MS, Ramya K. Evaluation of hypolipidemic effects of Lycium barbarum (goji berry) in a murine model. J Nat Remedies. 2013,13(1):4-8. 
Reeve VE, Allanson M, Arun SJ, Domanski D, Painter N. Mice drinking goji berry juice (Lycium barbarum) are protected from UV radiation-induced skin damage via antioxidant pathways. Photochem Photobiol Sci. 2010;9(4):601-7.

Sajjadi SE, Pestechian N, Kazemi M, Mohaghegh M-A, Hosseini-Safa A. Evaluation of the antimalarial effect of Ferulago angulata (Schlecht.) Boiss. extract and suberosin epoxide against plasmodium berghei in comparison with chloroquine using in-vivo test. Iran J Pharm Res. 2016;15(3):515-21.

Silva JCF, Degáspari CH. Propriedades nutricionais e efeitos adversos da "goji berry" (Lycium barbarum L.). Visão Acadêmica. 2014;15(3):67-80.

Tímaco ACE. Impacto de diferentes tempos de maceração na qualidade físico-química e aceitação de vinhos 'Syrah' produzidos no Vale do São Francisco. São Paulo, 2012. Trabalho de Conclusão de Curso - Escola Superior de Agricultura Luiz de Queiróz - Universidade São Paulo.
Velasco MVR, Okubo FR, Ribeiro ME, Steiner D, Bedin V. Rejuvenescimento da pele por peeling químico: enfoque no peeling de fenol. An Bras Derm. 2004;79(1):91-9.

Vieira RP, Fernandes AR, Kaneko TM, Consiglieri VO, Pinto CASO, Pereira CSC, Baby AR, Velasco MVR. Physical and physicochemical stability evaluation of cosmetic formulations containing soybean extract fermented by Bifidobacterium animalis. Braz J Pharm Sci. 2009;45(3):515-25.

Zhao H, Bojanowski K. Dermatologic Uses and effects of Lycium barbarum. In: Chang RC-C, So K-F, editors. Lycium barbarum and human health. Dordrecht: Springer; 2015. p.7984.

Received for publication on $11^{\text {th }}$ July 2017 Accepted for publication on $02^{\text {nd }}$ July 2018 